\title{
Surface-aerosol stability and pathogenicity of diverse MERS-CoV strains from 2012 - 2018
}

Neeltje van Doremalen ${ }^{* 1}$, Michael Letko ${ }^{* 111 \#}$, Robert J. Fischer ${ }^{1}$, Trenton Bushmaker ${ }^{1}$, Claude Kwe Yinda ${ }^{1}$, Jonathan Schulz ${ }^{1}$, Stephanie N. Seifert ${ }^{1,11}$, Nam Joong Kim², Maged G Hemida ${ }^{3,4}$, Ghazi Kayali ${ }^{5}$, Wan Beom Park ${ }^{2}$, Ranawaka APM Perera ${ }^{6}$, Azaibi Tamin $^{7}$, Natalie J. Thornburg ${ }^{7}$, Suxiang Tong ${ }^{7}$, Krista Queen ${ }^{7}$, Maria D. van Kerkhove ${ }^{8}$, Young Ki Choi ${ }^{9}$, Myoung-don Oh ${ }^{2}$, Abdullah M. Assiri ${ }^{10}$, Malik Peiris ${ }^{6}$, Susan I. Gerber ${ }^{7}$, Vincent J. Munster ${ }^{1 \#}$

1. Laboratory of Virology, Division of Intramural Research, National Institute of Allergy and Infectious Diseases, National Institutes of Health, Hamilton, MT, 59840, USA

2. Department of Internal Medicine, Seoul National University College of Medicine, Seoul, South Korea

3. Department of Microbiology, College of Veterinary Medicine, King Faisal University, AlHasa, Saudi Arabia

4. Department of Virology, Faculty of Veterinary Medicine, Kafrelsheikh University, Kafrelsheikh, Egypt

5. Department of Epidemiology, Human Genetics, and Environmental Sciences, University of Texas Health Sciences Center, Department of Epidemiology, Human Genetics, and Environmental Sciences, Houston, Texas

6. School of Public Health, University of Hong-Kong, Hong Kong SAR, China

7. Division of Viral Diseases, National Center for Immunization and Respiratory Diseases, Centers for Disease Control and Prevention, Atlanta, GA, USA.

8. Department of Infectious Hazards Management, Health Emergencies Programme, World Health Organization, Geneva, Switzerland.

9. College of Medicine and Medical Research Institute, Chungbuk National University, Cheongju City, Republic of Korea

10. Infection Prevention and Control, Assistant Deputy Minister, Preventive Health, Ministry of Health, Riyadh, Saudi Arabia

11. Paul G. Allen School of Global Animal Health, Washington State University, Pullman, WA, 99111, USA

* These authors contributed equally to this article

\# Corresponding author:

Dr. Michael Letko

Paul G. Allen School of Global Animal Health

Washington State University

Pullman, WA, 99164

Tel: (509) 335-4058

Email: michael.letko@wsu.edu 


\section{Abstract}

Middle East Respiratory Syndrome coronavirus (MERS-CoV) is a coronavirus that infects both humans and dromedary camels and is responsible for an ongoing outbreak of severe respiratory illness in humans in the Middle East. While some mutations found in camel-derived MERS-CoV strains have been characterized, the majority of natural variation found across MERS-CoV isolates remains unstudied. Here we report on the environmental stability, replication kinetics and pathogenicity of several diverse isolates of MERS-CoV as well as SARS-CoV-2 to serve as a basis of comparison with other stability studies. While most of the MERS-CoV isolates exhibited similar stability and pathogenicity in our experiments, the camel derived isolate, $\mathrm{C} / \mathrm{KSA} / 13$, exhibited reduced surface stability while another camel isolate, $\mathrm{C} / \mathrm{BF} / 15$, had reduced pathogenicity in a small animal model. These results suggest that while betacoronaviruses may have similar environmental stability profiles, individual variation can influence this phenotype, underscoring the importance of continual, global viral surveillance.

\section{Introduction}

Middle East respiratory syndrome coronavirus (MERS-CoV) was first discovered in 2012 and continues to cause outbreaks in the Middle East as a result of frequent spillover from dromedary camels to humans. MERS-CoV has a mortality rate of $\sim 35 \%$ and has spread to 27 countries $(1,2)$. While dromedary camels have been shown to be the animal reservoir, phylogenetic analysis has shown that humans are a dead-end host (3). Approximately $41 \%$ of MERS-CoV cases in the Kingdom of Saudi Arabia (KSA) are primary, resulting from direct camel-to-human transmission (4). To date, MERS-CoV has been detected in camels in Burkina Faso, Egypt, Ethiopia, Jordan, Kenya, Morocco, Nigeria, Saudi Arabia, Senegal, Sudan, 
Tunisia, and Uganda (5-13). While MERS-CoV has been isolated from camels in Africa, there are no reports of zoonotic transmission to humans, unlike what has been observed in the Middle East (9).

Human-to-human transmission of MERS-CoV has been reported but is inefficient and primarily occurs in hospital settings and within households (14). The exact route of transmission between humans is currently still unclear. It is possible that direct contact with infected individuals, as well as fomite and aerosol transmission all collectively contribute to viral transmission. Epidemiological studies have mapped indirect patient contact within hospitals, providing evidence for aerosol and hospital-worker mediated spread (15-18). The largest outbreak of MERS-CoV outside of the Middle East occurred in South Korea. A single traveler from the Middle East brought MERS-CoV to South Korea, resulting in 185 subsequent infections (19).

Coronaviruses are the largest non-segmented RNA-based viruses identified, with genome sizes averaging around 30kB. Even though coronavirus polymerase has a proofreading function, coronaviruses within the same species are polymorphic. A recent study found approximately $99 \%$ nucleotide similarity as well as small deletions in nonstructural proteins between various isolates collected in the Middle East and North Africa (20). While this variation may seem minimal, $1 \%$ is equivalent to 300 nucleotide changes in the $30 \mathrm{kB}$ genome. Indeed, many of these changes are nonsynonymous and are distributed throughout the viral genome. As previously shown, single amino acid changes in the viral genome can result in profoundly varying phenotypes in viral replication (21). Additionally, one study has aimed to functionally characterize some of these MERS-CoV strain differences, with a particular focus on ORF deletions, and found significant effects in the virus' ability to antagonize host innate immune pathways, translating to viral attenuation in an animal model (20). Given that MERS-CoV continues to cause outbreaks and evolve, these findings underscore the importance of 
characterizing how MERS-CoV genetic variation alters viral replication, pathogenicity and stability.

Here we expand on previous work from others by testing a broad panel of viral isolates collected from both humans and camels, representing every major geographic region with MERS-CoV outbreaks and spanning from early to contemporary outbreaks. Because MERS-CoV spreads within households and hospitals, we characterized and compared viral phenotypes with immediate implications for public health. We focused on environmental stability both in aerosols as well as surface stability on common materials found in hospitals, replication kinetics in immortalized human cell lines and primary human airway epithelial cultures, as well as pathogenicity in a transgenic mouse model our lab previously developed to test vaccine efficacy (22). For the environmental stability studies, we included SARS-CoV-2 to allow better comparison of these findings with previously published stability studies(23).

\section{Methods}

\section{Ethical approval}

Animal experiment approval was obtained by the Institutional Animal Care and Use Committee (IACUC) at Rocky Mountain Laboratories. All animal experiments were executed in an Association for Assessment and Accreditation of Laboratory Animal Care (AALAC)-approved facility, following the guidelines in NIH Guide for the Care and Use of Laboratory Animals, Animal Welfare Act, United States Department of Agriculture and United States Public Health Service Policy on Humane Care and Use of Laboratory Animals. The Institutional Biosafety Committee (IBC) approved work with MERS-CoV strains under BSL3 conditions. Sample inactivation was performed according to IBC-approved standard operating procedures. 


\section{Viral stock propagation}

MERS-CoV and SARS-CoV-2 strains were obtained from different collaborators and passaged once in VeroE6 cells in DMEM (Sigma Aldrich) supplemented with $2 \%$ fetal bovine serum (Fisher Scientific), $1 \mathrm{mM} \mathrm{L-glutamine} \mathrm{(Thermo} \mathrm{Fischer),} 50 \mathrm{U} / \mathrm{ml}$ penicillin (Thermo Fischer) and $50 \mu \mathrm{g} / \mathrm{ml}$ streptomycin (Thermo Fischer). SARS-CoV-2 strain nCoV-WA1-2020 (MN985325.1) was provided by CDC, Atlanta, USA. Virus propagation was performed in VeroE6 cells in DMEM supplemented with $2 \%$ fetal bovine serum, 1 mM L-glutamine, $50 \mathrm{U} / \mathrm{mL}$ penicillin and $50 \mu \mathrm{g} / \mathrm{mL}$ streptomycin. VeroE6 cells were maintained in DMEM supplemented with 10\% fetal bovine serum, $1 \mathrm{mM}$ L-glutamine, 50 $\mathrm{U} / \mathrm{mL}$ penicillin and $50 \mu \mathrm{g} / \mathrm{mL}$ streptomycin. Virus stocks were clarified by centrifugation and frozen at $-80^{\circ} \mathrm{C}$. Virus titrations were performed by end-point titration in VeroE6 cells inoculated with tenfold serial dilutions of virus. Cytopathic effect was scored at D5 (MERS-CoV) or D6 (SARS-CoV-2) and TCID 50 was calculated from four replicates by the Spearman-Karber method (24).

\section{Sequencing stocks}

All experiments, through second-strand cDNA synthesis, were performed in a BSLII cabinet for safety considerations. MERS-CoV samples were treated with RiboZero H/M/R rRNA (Illumina, San Diego, CA) depletion mix following the manufacturer's instructions. After Ampure RNACleanXP (Beckman Coulter, Brea, CA) purification, the enriched RNA was eluted and assessed on a BioAnalyzer RNA Pico Chip (Agilent Technologies, Santa Clara, CA). These samples were then used to 
prepare second-strand cDNA, following the Truseq Stranded mRNA Library Preparation Guide, Revision E., (Illumina, San Diego, CA). To remove any remaining positive-strand RNA, samples were treated with RiboShredder RNase Blend. After AMpure XP purification (Beckman Coulter, Brea, CA), samples were analyzed on a RNA Pico chip to confirm RNA removal and the ends were adenylated following manufacturer's recommendations. Final libraries were visualized on a BioAnalyzer DNA1000 chip (Agilent Technologies, Santa Clara, CA) and quantified using KAPA Library Quant Kit (Illumina) Universal qPCR Mix (Kapa Biosystems, Wilmington, MA) on a CFX96 RealTime System (BioRad, Hercules, CA). Libraries were pooled together in equimolar concentrations and sequenced on the MiSeq (Ilumina, Inc, San Diego, CA) using onboard cluster generation and $2 \times 250$ paired-end sequencing. The cluster density was at $454 \mathrm{k} / \mathrm{mm} 2$ per lane resulting in 8.7 Million reads passing filter per run with an average $85 \%>$ Q30.

\section{Phylogenetics}

All available MERS-CoV genome sequences were downloaded from GenBank and curated to remove sequences that were not independently sampled. The GenBank MERS-CoV sequences were aligned with the consensus sequences for MERS-CoV isolates used in this study using the MAFFT v. 7.388 plugin (25) in Geneious Prime. The phylogenetic tree was inferred using the maximum likelihood method under the GTR + gamma model of nucleotide substitution with 1000 bootstrap replicates implemented with PhyML version 3.3.20190321. 
Stability of MERS-CoV on surface and in aerosols

Four different surfaces were evaluated: polypropylene (ePlastics), AISI 304 alloy stainless steel (Metal Remnants), copper (99.9\%) (Metal Remnants) and silver (99.9\%) (Sigma-Aldrich). Discs with a radius of $15 \mathrm{~mm}$ were cut out, sterilized and placed in 24well plates. Each disc received $50 \mu$ of MERS-CoV at a titer of $10^{5} \mathrm{TCID}_{50} / \mathrm{mL}$. At appropriate times, $1 \mathrm{~mL}$ of DMEM was added to the well, aliquoted and stored at $-80^{\circ} \mathrm{C}$. All samples were titrated on VeroE6 cells.

Virus stability in aerosols was determined as described previously (26). Briefly, the collison nebulizer used to produce aerosols was loaded with $10^{6.5} \mathrm{TCID}_{50} / \mathrm{ml}$ of MERSCoV in DMEM containing 2\% FBS. Aerosols were maintained in the Goldberg drum and samples were collected at 0-, 30-, 60-, 120- and 180-minutes post aerosolization by passing air at $6 \mathrm{~L} / \mathrm{min}$ for 30 seconds from the drum through a $47 \mathrm{~mm}$ gelatin filter (Sartorius). Filters were dissolved in $10 \mathrm{~mL}$ of DMEM containing $10 \% \mathrm{FBS}$ and stored at $-80^{\circ} \mathrm{C}$. All samples were titrated on VeroE6 cells.

Replication of MERS-CoV strains in vitro

VeroE6 cells were plated in 6-well plates and inoculated with an $\mathrm{MOI}$ of 0.01 . Supernatant samples were obtained at 8, 24, 48 and 72 hours post infection (h.p.i.). Human airway epithelium inserts (HAE, Epithelix) were maintained as specified by manufacturer. HAEs were washed with $200 \mu$ of phosphate-buffered saline for 30 minutes, followed by inoculation with MERS-CoV at an MOI of 0.1 . Samples were obtained at $8,24,48,72$, and 96 h.p.i. 


\section{Animal experiments}

Transgenic balb/c mice expressing human DPP4 were inoculated intranasally (I.N.) with $10^{3} \mathrm{TCID}_{50}$ MERS-CoV. Mice were weighed and oropharyngeal swabs were taken daily. At D3, four mice were euthanized, and lung tissue was harvested. The remaining six mice were monitored for survival. Mice were euthanized upon presence of severe disease signs (e.g. hunched posture, lack of movement) or $>20 \%$ of weight loss.

RNA extraction and quantitative reverse-transcription polymerase chain reaction

Tissues were homogenized and RNA was extracted using the RNeasy method (Qiagen) according to the manufacturer's instructions. Swabs were added to $1 \mathrm{~mL}$ of DMEM, vortexed, and $140 \mu \mathrm{l}$ was utilized for RNA extraction using the QiaAmp Viral RNA kit on the QIAxtractor. MERS-CoV viral RNA was detected via the UpE MERSCoV assay (27) using the Rotor-GeneTM probe kit (Qiagen). MERS-CoV dilutions with known genome copies were run in parallel to allow calculation of genome copies in samples.

\section{Histology and immunohistochemistry}

Necropsies and tissue sampling were performed according to IBC-approved protocols. Lungs were perfused with $10 \%$ formalin and processed for histologic review. Harvested tissues were fixed for a minimum of seven days in $10 \%$ neutral-buffered formalin and then embedded in paraffin. Tissues were processed using a VIP-6 Tissue Tek, (Sakura Finetek, USA) tissue processor and embedded in Ultraffin paraffin polymer (Cancer Diagnostics, Durham, NC). Samples were sectioned at $5 \mu \mathrm{m}$, and resulting slides were 
stained with hematoxylin and eosin. Specific anti-CoV immunoreactivity was detected using MERS-CoV nucleocapsid protein rabbit antibody (Sino Biological Inc.) at a 1:4000. The tissues were processed for immunohistochemistry using the Discovery ULTRA automated IHC/ISH staining instrument (Ventana Medical Systems) with a Discovery ChromoMap DAB (Ventana Medical Systems) kit, scanned with the Aperio ScanScope AT2 (Aperio Technologies, Inc.) and the entire section analyzed with the ImageScope Positive Pixel Count algorithm (version 9.1). All tissue slides were evaluated by a board-certified veterinary anatomic pathologist.

\section{Statistical analyses}

All analyses were done using GraphPad Prism version 7.05 for Windows. All strains were compared to EMC/12. Linear regression was determined for the mean value of three runs per virus. Statistical significance was determined using ordinary one-way ANOVA followed by Bonferonni's multiple comparisons test or a two-way unpaired student's t-test.

\section{Results}

Stability of different MERS-CoV strains in aerosols or as fomites comparted to SARSCoV-2

We utilized eight different MERS-CoV strains and one SARS-CoV-2 strain (SARS-CoV-2 strain nCoV-WA1-2020 (MN985325.1)) in the current study. Five MERSCoV strains were isolated from human cases and three strains were isolated from dromedary camels. Strains were isolated between 2012 and 2018, and originated from 
the Middle East (5), Africa (2) or South Korea (1) (Table 1). All originally obtained viruses were passaged once in VeroE6 cells. Virus stocks were sequenced on the MiSeq. Mutations compared to the published sequence are detailed in Table 1.

Available full-length MERS-CoV sequences were downloaded from Genbank. A phylogenetic maximum likelihood tree was constructed of the GenBank MERS-CoV sequences and the consensus sequences for the MERS-CoV isolates. The investigated MERS-CoV strains were distributed throughout the phylogenetic tree (Figure 1) and thus represent a broad sample of known genetic variation within currently circulating MERS-CoV strains.

Stability of MERS-CoV strains was determined in aerosols as well as in fomites and compared to SARS-CoV-2. We investigated the stability of MERS-CoV as fomites on four different surfaces: polypropylene, stainless-steel, copper and silver. These surfaces were chosen as they represent commonly encountered surfaces in hospital environments or could function as a virocidal.

Back-titrations of all virus strains showed comparable starting virus titers. Stability of MERS-CoV on polypropylene and stainless-steel surfaces was similar to results previously reported for MERS-CoV and SARS-CoV-2 stability on surfaces (23, 28), except for strain $\mathrm{C} / \mathrm{KSA} / 13$. Infectious virus titers of $\mathrm{C} / \mathrm{KSA} / 13$ were significantly lower compared to EMC/12 on polypropylene (0,1, and 24hrs) and stainless-steel surfaces $(0,24$, and $48 \mathrm{hrs})$. In contrast, infectious virus titers were low for all strains on copper and silver surfaces at $24 \mathrm{hrs}$. Linear regression was calculated for the first $24 \mathrm{hrs}$ for each surface, and loss of infectious virus was significantly higher on copper and 
silver surfaces than on polypropylene and stainless-steel surfaces $(-0.11576,-0.08744$, -0.0529 , and -0.0469 respectively) (Figure $2 A)$.

All MERS-CoV strains were aerosolized in a Goldberg drum, samples were taken at $0,30,60,120$ and 180 min post aerosolization and titrated and compared with SARSCoV-2. No significant differences in linear regression of loss of infectious virus in aerosols was detected between strains $(\mathrm{EMC} / 12=-0.00419 ; \mathrm{U} / 14=-0.00781 ; \mathrm{KSA} / 15$ $=-0.00594 ; \mathrm{SK} / 15=-0.00682 ; \mathrm{KSA} / 18=-0.00527 ; \mathrm{C} / \mathrm{KSA} / 13=-0.00639 ; \mathrm{C} / \mathrm{E} / 13=-$ 0.00671; C/BF/15 = -0.00477). For all MERS-CoV strains, infectious virus could still be detected at 180 minutes post aerosolization (Figure 2B).

In vitro replication of different MERS-CoV strains

Growth of all strains was then compared in two different in vitro cell systems: VeroE6 cells and HAE cultures. All strains were compared to the reference strain EMC/12 using a two-tailed unpaired Student's t-test. At 48 hpi, C/KSA/13 and KSA/15 grew to significantly higher titers than EMC/12 in VeroE6 cells. At 72 hpi, C/KSA/13 and $\mathrm{C} / \mathrm{BF} / 15$ grew to significantly lower titers than EMC/12 in HAE cultures. No other significant differences were observed in either VeroE6 cells or HAE cultures. While not always statistically significant, all camel-derived viruses had reduced replication kinetics as compared to EMC/12 in HAE cells at 24-72 hpi (Figure 3).

Disease progression of different MERS-CoV strains in hDPP4 transgenic mice MERS-CoV enters cells expressing the receptor human dipeptidyl peptidase IV (hDPP4). Our lab previously developed transgenic mice expressing hDPP4 to test MERS-CoV vaccine efficacy (22). Ten mice per group were inoculated I.N. with $10^{3}$ 
$\mathrm{TCID}_{50}$ MERS-CoV per mouse. Mice started to lose weight on D2 to D5. Body weight kept decreasing for all groups, except for the mice inoculated with $\mathrm{C} / \mathrm{BF} / 15$ : only one mouse continued to lose weight (Figure 4A). This was accompanied by similar signs of disease across all groups; ruffled coat, increased breathing rate, reluctance to move, and hunched posture. No such signs were observed for mice inoculated with C/BF/15 that did not lose weight. Survivors were only found in the group inoculated with SK/15 (1 out of 6 ) and the group inoculated with $\mathrm{C} / \mathrm{BF} / 15$ (5 out of 6 ). Average time to death was similar for all groups, excluding C/BF/15 (EMC/12 = 7.33; U/14 = 6.5; KSA/15 = 7; $\mathrm{SK} / 15=7.6 ; \mathrm{KSA} / 18=7.67 ; \mathrm{C} / \mathrm{KSA} / 13=7.5 ; \mathrm{C} / \mathrm{E} / 13=8)($ Figure $4 B)$.

Oral swabs were taken at D1 to D7 post inoculation and viral RNA was measured via qRT-PCR. The total amount of viral shedding was determined per group. No significant differences were found in the amount of shedding between different groups (Figure $4 C-D$ ). Viral gRNA and sgRNA was then measured via qRT-PCR in lung tissue obtained from four animals per group at D3. gRNA was significantly lower in lung tissue of mice inoculated with $\mathrm{SK} / 15, \mathrm{C} / \mathrm{E} / 15$ and $\mathrm{C} / \mathrm{BF} / 15$. sgRNA was only significantly lower in lung tissue of mice inoculated with $\mathrm{C} / \mathrm{BF} / 15$ (Figure $4 E-F$ ).

Lung pathology was then examined by a board-certified veterinary pathologist blinded to study group allocation. No differences in pathology were observed. Animals rarely showed pulmonary pathology at $\mathrm{D} 3$, however animals that had lesions showed only a minimal and random lymphocytic infiltrate. Immunohistochemistry detecting MERS-CoV antigen was expressed rarely or randomly scattered in pulmonary tissue type I and II pneumocytes and not located in areas of inflammation. Morphometric 
bioRxiv preprint doi: https://doi. org/10.1101/2021.02 11.429193; this version posted February 12, 2021. The copyright holder for this preprint (which was not certified by peer review) is the author/funder. This article is a US Government work. It is not subject to copyright under 17 USC 105 and is also made available for use under a CCO license.

analysis of pulmonary tissue with immunoreactivity revealed no significant difference between groups (Figure 4G). 


\section{Discussion}

The respiratory nature of MERS-CoV, in combination with its high mortality rate and frequent spillover from dromedary camels, position this virus as a potential threat to global health. The ongoing MERS-CoV endemic in the Middle East and subsequent discovery of the virus in camel herds across Africa has resulted in a wealth of publiclyavailable genetic data for various viral strains and isolates. Critically, a small number of studies have shown that genetic variation in MERS-CoV can drastically effect viral phenotypes including replication kinetics and pathogenicity $(21,29,30)$. These findings highlight the need for MERS-CoV surveillance and, importantly, the assessment of new strains as they are isolated for mutations that increase spread, transmission and pathogenicity. In this study, we assessed several viral phenotypes as they relate to public health, in an attempt to better inform public health policy making with regards to MERS- and other respiratory-borne, human CoVs such as SARS-CoV-2. We assembled and tested a panel of diverse MERS-CoV viral isolates. Because MERSCoV frequently spills over into the human population, we chose to include both humanand camel-derived strains (Table 1, Figure 1).

Nosocomial spread is at the center of MERS-CoV outbreaks. Therefore, we first assessed the stability of the virus on various surface material types commonly found in hospitals (polypropylene plastic and stainless steel) as well as materials with potential antiviral and known antimicrobial properties (silver and copper) $(31,32)$. Regardless of the surface material tested, $\mathrm{C} / \mathrm{KSA} / 13$ was the least stable over time and fell below detectable levels by 24 hours (Figure $2 A$ ). As shown previously(23), all virus strains tested had notably reduced stability when left on copper. This finding was repeated on 
silver surfaces, with the copper surface proving most effective at reducing viral titers (Figure 2A, right panels). While copper and silver are generally appreciated for their antibacterial properties, copper has recently been shown to also have antiviral properties against influenza A H1N1 and SARS-CoV-2 (33-35). The exact mechanism of copper's antiviral properties is still unclear, but may be related to the formation of hydroxyl radicals by copper ions when in aqueous solution (35). Silver-based nanoparticles have been shown to be antiviral for human immunodeficiency virus-1 (36), herpes simplex virus 2 (37), hepatitis B virus (38), respiratory syncytial virus (39), and monkey pox virus (40). Regardless of the mechanism, taking advantage of the antiviral properties of copper and silver could be a relatively straightforward method to decrease nosocomial transmission. Indeed, both silver and copper can be used for coating medical tools (41), and commonly touched items such as bed rails, door handles and intravenous poles (42). These findings appear to be more broadly applicable for other coronaviruses, as we observed similar results for SARS-CoV-2 (figure 2) (23). Further research should be invested in determining coronavirus susceptibility to coppermediated inactivation.

MERS-CoV infects the lower respiratory tract in humans, and while the exact route of transmission has not been proven in a laboratory setting, it is likely to occur through aerosols and fomites (43). Studies have suggested that a hospital air-handling system may have contributed to nosocomial spread during the 2015 MERS-CoV outbreak in South Korea $(16,43)$ and our group has previously shown that the virus can remain viable suspended in air for up to 10 minutes (28). We tested aerosol stability over time for a diverse set of isolates with a Goldberg drum and observed that all 
viruses remained viable for a minimum of 180 minutes with approximately a log10 reduction in viral titer observed on average within the collected aerosols (Figure 2B). Even though we did not observe major differences in this study, strain stability is an important phenotype to continue monitoring, as mutations in viral capsid proteins have been shown to enhance environmental stability of bacteriophages, Dengue virus, and transmissible gastroenteritis virus (44-46). Because MERS-CoV isolates contain polymorphisms throughout the entire viral genome, including the structural proteins that form virions, it is still possible mutations may arise that influence overall virus particle stability. C/KSA/13, which showed reduced stability on surfaces in our experiments, contains polymorphisms in ORF1b, the spike glycoprotein, and the virion matrix protein in comparison to the other strains tested. Tracking and assessing the stability of coronavirus strains, even if to only rule out this possibility, will aid in our understanding of coronavirus variant spread during outbreaks, including the ongoing SARS-CoV-2 pandemic.

We tested viral replication kinetics of our virus panel in both VeroE6 cells as well as primary HAE cells (Figure 3). All virus isolates came up to similar titers on the VeroE6 cells by 72 hours, however $\mathrm{KSA} / 15$ and $\mathrm{C} / \mathrm{KSA} / 13$ had a higher titer than EMC/12 by 48 hours post infection. Albeit not significant, C/BF/15 has a lower viral titer than EMC/12 at 48 and 72 hpi. These results are in good agreement with a previous study showing that C/BF/15 has impaired replication (20). In primary HAE cultures, all camel-derived viral isolates had reduced replication kinetics compared to EMC/12 (Figure 3B). More studies are needed with these camel-derived isolates to determine if their difference in replication kinetics results from a comparison with EMC12, which has 
well-described tissue culture adaptations, or to see if MERS-CoV may adapt in humans after transmission from camels.

Last, we tested our panel of viruses in a transgenic hDPP4 mouse model (22). We have previously shown that MERS-CoV replicates in type I and II pneumocytes within in the lower respiratory tract of this animal model (22). While MERS-CoV disease progression does not involve the central nervous system in humans, this small animal model is suitable for vaccine candidate testing, with animal survival or viral-induced death as a binary readout for vaccine efficacy. With the exception of C/BF/15 and SK/15, all strains tested were uniformly lethal in these animals, resulting in similar weight loss profiles and histopathology scores (Figure 4). MERS-CoV C/BF/15 contains a deletion in open reading frame $4 b(\mathrm{ORF} 4 \mathrm{~b})$, which has been shown in a similar mouse model to result in impaired suppression of the host interferon response and increased type I and type III interferon signaling (20). Taken together, these results pave the way for testing MERS-CoV vaccine candidates for broadly neutralizing potential in this animal model $(22,47)$.

Our results with MERS-CoV C/KSA/13 suggest there may be a potential tradeoff between environmental surface stability and replication kinetics. Notably, this was observed for a camel-derived isolate, and we did not observe similar phenotypic relationships for the other strains tested (Figure 2, 3). Future research efforts with camel-derived viruses and more closely related human-derived viruses could reveal whether adaptations are likely to occur after zoonosis. Our previous viral stability results with SARS-CoV-2 and now these findings with MERS-CoV suggest copper should be incorporated more in hospital settings, particularly in areas of high contact between 
hospital workers and MERS patients, such as door handles, bed rails, and medical tools (23). Overall, we observed a range of stability, replication and pathogenesis phenotypes between different MERS-CoV isolates, underscoring the importance of continued surveillance of this virus and other coronaviruses such as SARS-CoV-2.

\section{Brief biography on the first authors:}

1. Dr. van Doremalen is a staff scientist in the Virus Ecology Section at the NIH's Rocky Mountain Laboratories. Her research has helped develop animal models and test next generation vaccines for emerging infectious diseases.

2. Dr. Letko is an assistant professor at Washington State University. His laboratory studies how viral-host molecular interactions contribute to the potential for zoonotic transmission of novel, animal-derived viruses. 


\section{References}

1. Zaki AM, van Boheemen S, Bestebroer TM, Osterhaus AD, Fouchier RA. 2012. Isolation of a novel coronavirus from a man with pneumonia in Saudi Arabia. N Engl J Med 367:1814-20.

2. WHO.

3. Cotten M, Watson SJ, Kellam P, Al-Rabeeah AA, Makhdoom HQ, Assiri A, Al-Tawfiq JA, Alhakeem RF, Madani H, AlRabiah FA, Al Hajjar S, Al-nassir WN, Albarrak A, Flemban H, Balkhy HH, Alsubaie S, Palser AL, Gall A, Bashford-Rogers R, Rambaut A, Zumla AI, Memish ZA. 2013. Transmission and evolution of the Middle East respiratory syndrome coronavirus in Saudi Arabia: a descriptive genomic study. Lancet 382:19932002.

4. Organization WH. 2019. MERS SITUATION UPDATE October 2019.

5. Zhang W, Zheng XS, Agwanda B, Ommeh S, Zhao K, Lichoti J, Wang N, Chen J, Li B, Yang XL, Mani S, Ngeiywa KJ, Zhu Y, Hu B, Onyuok SO, Yan B, Anderson DE, Wang LF, Zhou P, Shi ZL. 2019. Serological evidence of MERS-CoV and HKU8-related CoV co-infection in Kenyan camels. Emerg Microbes Infect 8:1528-1534.

6. van Doremalen N, Hijazeen ZS, Holloway P, Al Omari B, McDowell C, Adney D, Talafha HA, Guitian J, Steel J, Amarin N, Tibbo M, Abu-Basha E, Al-Majali AM, Munster VJ, Richt JA. 2017. High Prevalence of Middle East Respiratory Coronavirus in Young Dromedary Camels in Jordan. Vector Borne Zoonotic Dis 17:155-159.

7. Shirato K, Melaku SK, Kawachi K, Nao N, Iwata-Yoshikawa N, Kawase M, Kamitani W, Matsuyama S, Tessema TS, Sentsui H. 2019. Middle East Respiratory Syndrome Coronavirus in Dromedaries in Ethiopia Is Antigenically Different From the Middle East Isolate EMC. Front Microbiol 10:1326.

8. Kandeil A, Gomaa M, Nageh A, Shehata MM, Kayed AE, Sabir JSM, Abiadh A, Jrijer J, Amr Z, Said MA, Byarugaba DK, Wabwire-Mangen F, Tugume T, Mohamed NS, Attar R, Hassan SM, Linjawi SA, Moatassim Y, Kutkat O, Mahmoud S, Bagato O, Shama NMA, El-Shesheny R, Mostafa A, Perera RA, Chu DK, Hassan N, Elsokary B, Saad A, Sobhy H, El Masry I, McKenzie PP, Webby RJ, Peiris M, Makonnen YJ, Ali MA, Kayali G. 2019. Middle East Respiratory Syndrome Coronavirus (MERS-CoV) in Dromedary Camels in Africa and Middle East. Viruses 11.

9. Farag E, Sikkema RS, Mohamedani AA, de Bruin E, Munnink BBO, Chandler F, Kohl R, van der Linden A, Okba NMA, Haagmans BL, van den Brand JMA, Elhaj AM, Abakar AD, Nour BYM, Mohamed AM, Alwaseela BE, Ahmed H, Alhajri MM, Koopmans M, Reusken C, Elrahman SHA. 2019. MERS-CoV in Camels but Not Camel Handlers, Sudan, 2015 and 2017. Emerg Infect Dis 25:2333-2335.

10. Chu DK, Poon LL, Gomaa MM, Shehata MM, Perera RA, Abu Zeid D, El Rifay AS, Siu LY, Guan Y, Webby RJ, Ali MA, Peiris M, Kayali G. 2014. MERS coronaviruses in dromedary camels, Egypt. Emerg Infect Dis 20:1049-53.

11. Alagaili AN, Briese T, Mishra N, Kapoor V, Sameroff SC, Burbelo PD, de Wit E, Munster VJ, Hensley LE, Zalmout IS, Kapoor A, Epstein JH, Karesh WB, Daszak P, Mohammed OB, Lipkin WI. 2014. Middle East respiratory syndrome coronavirus infection in dromedary camels in Saudi Arabia. MBio 5:e00884-14.

12. Miguel E, Chevalier V, Ayelet G, Ben Bencheikh MN, Boussini H, Chu DK, El Berbri I, Fassi-Fihri O, Faye B, Fekadu G, Grosbois V, Ng BC, Perera RA, So TY, Traore A, 
Roger F, Peiris M. 2017. Risk factors for MERS coronavirus infection in dromedary camels in Burkina Faso, Ethiopia, and Morocco, 2015. Euro Surveill 22.

13. Chu DK, Oladipo JO, Perera RA, Kuranga SA, Chan SM, Poon LL, Peiris M. 2015. Middle East respiratory syndrome coronavirus (MERS-CoV) in dromedary camels in Nigeria, 2015. Euro Surveill 20.

14. Hui DS, Azhar EI, Kim YJ, Memish ZA, Oh MD, Zumla A. 2018. Middle East respiratory syndrome coronavirus: risk factors and determinants of primary, household, and nosocomial transmission. Lancet Infect Dis 18:e217-e227.

15. Assiri A, McGeer A, Perl TM, Price CS, Al Rabeeah AA, Cummings DA, Alabdullatif ZN, Assad M, Almulhim A, Makhdoom H, Madani H, Alhakeem R, Al-Tawfiq JA, Cotten M, Watson SJ, Kellam P, Zumla AI, Memish ZA, Team KM-CI. 2013. Hospital outbreak of Middle East respiratory syndrome coronavirus. N Engl J Med 369:407-16.

16. Cho SY, Kang JM, Ha YE, Park GE, Lee JY, Ko JH, Lee JY, Kim JM, Kang CI, Jo IJ, Ryu JG, Choi JR, Kim S, Huh HJ, Ki CS, Kang ES, Peck KR, Dhong HJ, Song JH, Chung DR, Kim YJ. 2016. MERS-CoV outbreak following a single patient exposure in an emergency room in South Korea: an epidemiological outbreak study. Lancet 388:9941001.

17. Chowell G, Abdirizak F, Lee S, Lee J, Jung E, Nishiura H, Viboud C. 2015. Transmission characteristics of MERS and SARS in the healthcare setting: a comparative study. BMC Med 13:210.

18. Hunter JC, Nguyen D, Aden B, Al Bandar Z, Al Dhaheri W, Abu Elkheir K, Khudair A, Al Mulla M, El Saleh F, Imambaccus H, Al Kaabi N, Sheikh FA, Sasse J, Turner A, Abdel Wareth L, Weber S, Al Ameri A, Abu Amer W, Alami NN, Bunga S, Haynes LM, Hall AJ, Kallen AJ, Kuhar D, Pham H, Pringle K, Tong S, Whitaker BL, Gerber SI, Al Hosani FI. 2016. Transmission of Middle East Respiratory Syndrome Coronavirus Infections in Healthcare Settings, Abu Dhabi. Emerg Infect Dis 22:647-56.

19. Kim KH, Tandi TE, Choi JW, Moon JM, Kim MS. 2017. Middle East respiratory syndrome coronavirus (MERS-CoV) outbreak in South Korea, 2015: epidemiology, characteristics and public health implications. J Hosp Infect 95:207-213.

20. Chu DKW, Hui KPY, Perera R, Miguel E, Niemeyer D, Zhao J, Channappanavar R, Dudas G, Oladipo JO, Traore A, Fassi-Fihri O, Ali A, Demissie GF, Muth D, Chan MCW, Nicholls JM, Meyerholz DK, Kuranga SA, Mamo G, Zhou Z, So RTY, Hemida MG, Webby RJ, Roger F, Rambaut A, Poon LLM, Perlman S, Drosten C, Chevalier V, Peiris M. 2018. MERS coronaviruses from camels in Africa exhibit region-dependent genetic diversity. Proc Natl Acad Sci U S A 115:3144-3149.

21. Letko M, Miazgowicz K, McMinn R, Seifert SN, Sola I, Enjuanes L, Carmody A, van Doremalen N, Munster V. 2018. Adaptive Evolution of MERS-CoV to Species Variation in DPP4. Cell Rep 24:1730-1737.

22. Munster VJ, Wells D, Lambe T, Wright D, Fischer RJ, Bushmaker T, Saturday G, van Doremalen N, Gilbert SC, de Wit E, Warimwe GM. 2017. Protective efficacy of a novel simian adenovirus vaccine against lethal MERS-CoV challenge in a transgenic human DPP4 mouse model. NPJ Vaccines 2:28.

23. van Doremalen N, Bushmaker T, Morris DH, Holbrook MG, Gamble A, Williamson BN, Tamin A, Harcourt JL, Thornburg NJ, Gerber SI, Lloyd-Smith JO, de Wit E, Munster VJ. 2020. Aerosol and Surface Stability of SARS-CoV-2 as Compared with SARS-CoV-1. N Engl J Med 382:1564-1567. 
24. Karber G. 1931. Article on the collective handling of pharmacological array effort. Naunyn-Schmiedebergs Archiv Fur Experimentelle Pathologie Und Pharmakologie 162:480-483.

25. Katoh K, Standley DM. 2013. MAFFT multiple sequence alignment software version 7: improvements in performance and usability. Mol Biol Evol 30:772-80.

26. Fischer RJ, Bushmaker T, Judson S, Munster VJ. 2016. Comparison of the Aerosol Stability of 2 Strains of Zaire ebolavirus From the 1976 and 2013 Outbreaks. J Infect Dis 214:S290-S293.

27. Corman VM, Eckerle I, Bleicker T, Zaki A, Landt O, Eschbach-Bludau M, van Boheemen S, Gopal R, Ballhause M, Bestebroer TM, Muth D, Muller MA, Drexler JF, Zambon M, Osterhaus AD, Fouchier RM, Drosten C. 2012. Detection of a novel human coronavirus by real-time reverse-transcription polymerase chain reaction. Euro Surveill 17.

28. van Doremalen N, Bushmaker T, Munster VJ. 2013. Stability of Middle East respiratory syndrome coronavirus (MERS-CoV) under different environmental conditions. Euro Surveill 18.

29. Douglas MG, Kocher JF, Scobey T, Baric RS, Cockrell AS. 2018. Adaptive evolution influences the infectious dose of MERS-CoV necessary to achieve severe respiratory disease. Virology 517:98-107.

30. Muth D, Corman VM, Roth H, Binger T, Dijkman R, Gottula LT, Gloza-Rausch F, Balboni A, Battilani M, Rihtaric D, Toplak I, Ameneiros RS, Pfeifer A, Thiel V, Drexler JF, Muller MA, Drosten C. 2018. Attenuation of replication by a 29 nucleotide deletion in SARS-coronavirus acquired during the early stages of human-to-human transmission. Sci Rep 8:15177.

31. Grass G, Rensing C, Solioz M. 2011. Metallic copper as an antimicrobial surface. Appl Environ Microbiol 77:1541-7.

32. Galdiero S, Falanga A, Vitiello M, Cantisani M, Marra V, Galdiero M. 2011. Silver nanoparticles as potential antiviral agents. Molecules 16:8894-918.

33. Noyce JO, Michels H, Keevil CW. 2007. Inactivation of influenza A virus on copper versus stainless steel surfaces. Appl Environ Microbiol 73:2748-50.

34. Minoshima M, Lu Y, Kimura T, Nakano R, Ishiguro H, Kubota Y, Hashimoto K, Sunada K. 2016. Comparison of the antiviral effect of solid-state copper and silver compounds. J Hazard Mater 312:1-7.

35. Fujimori Y, Sato T, Hayata T, Nagao T, Nakayama M, Nakayama T, Sugamata R, Suzuki K. 2012. Novel antiviral characteristics of nanosized copper(I) iodide particles showing inactivation activity against 2009 pandemic H1N1 influenza virus. Appl Environ Microbiol 78:951-5.

36. Lara HH, Ayala-Nunez NV, Ixtepan-Turrent L, Rodriguez-Padilla C. 2010. Mode of antiviral action of silver nanoparticles against HIV-1. J Nanobiotechnology 8:1.

37. Hu RL, Li SR, Kong FJ, Hou RJ, Guan XL, Guo F. 2014. Inhibition effect of silver nanoparticles on herpes simplex virus 2. Genet Mol Res 13:7022-8.

38. Lu L, Sun RW, Chen R, Hui CK, Ho CM, Luk JM, Lau GK, Che CM. 2008. Silver nanoparticles inhibit hepatitis B virus replication. Antivir Ther 13:253-62.

39. Yang XX, Li CM, Huang CZ. 2016. Curcumin modified silver nanoparticles for highly efficient inhibition of respiratory syncytial virus infection. Nanoscale 8:3040-8. 
40. Rogers J, Parkinson C, YW C, Speshock J, Hussain S. 2008. A Preliminary Assessment of Silver Nanoparticle Inhibition of Monkeypox Virus Plaque Formation. Nanoscale Res Lett 3(4):129-133.

41. Cyphert EL, von Recum HA. 2017. Emerging technologies for long-term antimicrobial device coatings: advantages and limitations. Exp Biol Med (Maywood) 242:788-798.

42. Salgado CD, Sepkowitz KA, John JF, Cantey JR, Attaway HH, Freeman KD, Sharpe PA, Michels HT, Schmidt MG. 2013. Copper surfaces reduce the rate of healthcare-acquired infections in the intensive care unit. Infect Control Hosp Epidemiol 34:479-86.

43. Kim SH, Chang SY, Sung M, Park JH, Bin Kim H, Lee H, Choi JP, Choi WS, Min JY. 2016. Extensive Viable Middle East Respiratory Syndrome (MERS) Coronavirus Contamination in Air and Surrounding Environment in MERS Isolation Wards. Clin Infect Dis 63:363-9.

44. Figueira-Mansur J, Aguilera EA, Stoque RM, Ventura GT, Mohana-Borges R. 2019. Mutations in the dimer interfaces of the dengue virus capsid protein affect structural stability and impair RNA-capsid interaction. Sci Rep 9:2829.

45. Escors D, Ortego J, Laude H, Enjuanes L. 2001. The membrane M protein carboxy terminus binds to transmissible gastroenteritis coronavirus core and contributes to core stability. J Virol 75:1312-24.

46. Lee KH, Miller CR, Nagel AC, Wichman HA, Joyce P, Ytreberg FM. 2011. First-step mutations for adaptation at elevated temperature increase capsid stability in a virus. PLoS One 6:e25640.

47. Alharbi NK, Padron-Regalado E, Thompson CP, Kupke A, Wells D, Sloan MA, Grehan K, Temperton N, Lambe T, Warimwe G, Becker S, Hill AVS, Gilbert SC. 2017. ChAdOx1 and MVA based vaccine candidates against MERS-CoV elicit neutralising antibodies and cellular immune responses in mice. Vaccine 35:3780-3788. 
Tables and Figures

Table 1. Details of MERS-CoV strains used in current study.

\begin{tabular}{|c|c|c|c|c|c|c|}
\hline Name & Host & Year & Location & Full name & $\begin{array}{l}\text { Access } \\
\text { number }\end{array}$ & SNPs \\
\hline EMC/12 & Human & 2012 & KSA & HCoV-EMC/2012 & JX869059 & $\begin{array}{l}\text { C6172T; C24059T; C24499A; } \\
\text { G27162A }\end{array}$ \\
\hline $\mathrm{U} / \mathbf{1 4}$ & Human & 2014 & USA & Hu/Florida/USA-2/Saudi Arabia/2014 & KP223131 & None \\
\hline KSA/15 & Human & 2015 & KSA & Hu/Hofuf/KSA-11002/2015 & KY688120 & None \\
\hline SK/15 & Human & 2015 & $\begin{array}{l}\text { South } \\
\text { Korea }\end{array}$ & Hu/Korea/Seoul/177-3/2015 & KX034100 & $\begin{array}{l}\text { C2149A; A6884G; T9566C; } \\
\text { G10155T; A11376T; } \\
\text { C14162T;C23041T; C26189T }\end{array}$ \\
\hline KSA/18 & Human & 2018 & KSA & Hu/Saudi Arabia/3015600912/2018 & MN723544 & C21149A; G22366A; C25009T \\
\hline C/KSA/13 & Camel & 2013 & KSA & Camel/Saudi Arabia/KFU-HKU1/2013 & KJ650297 & C25207T; C27875T \\
\hline $\mathrm{C} / \mathrm{E} / \mathbf{1 3}$ & Camel & 2013 & Egypt & Camel/Egypt/NRCE/HKU270/2013 & KJ477103 & T16306C; C24100T; 26880T \\
\hline $\mathrm{C} / \mathrm{BF} / 15$ & Camel & 2015 & $\begin{array}{l}\text { Burkina } \\
\text { Faso }\end{array}$ & $\begin{array}{l}\text { Camel/Burkina Faso/CIRAD- } \\
\text { HKU785/2015 }\end{array}$ & MG923471 & M29358C \\
\hline
\end{tabular}




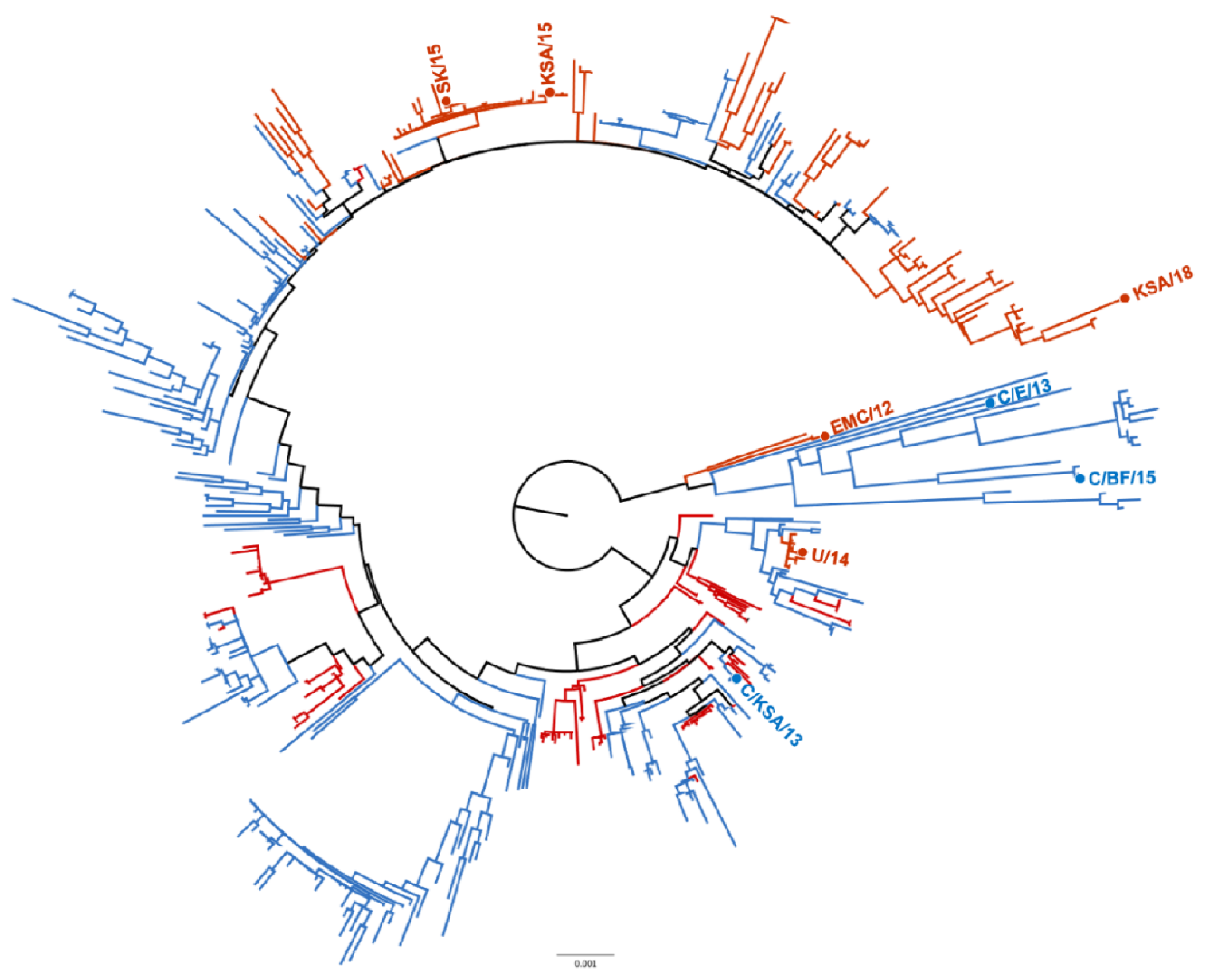

Figure 1. Phylogenetic tree of MERS-CoV strains. Maximum likelihood tree of 446 full MERSCoV genomes showing distribution of isolates used in this study. Human-derived MERS-CoV isolates used in this study are highlighted in red, camel-derived MERS-CoV isolates are highlighted in blue. Phylogenetic tree reconstructed with PhyML and rooted at the midpoint. 

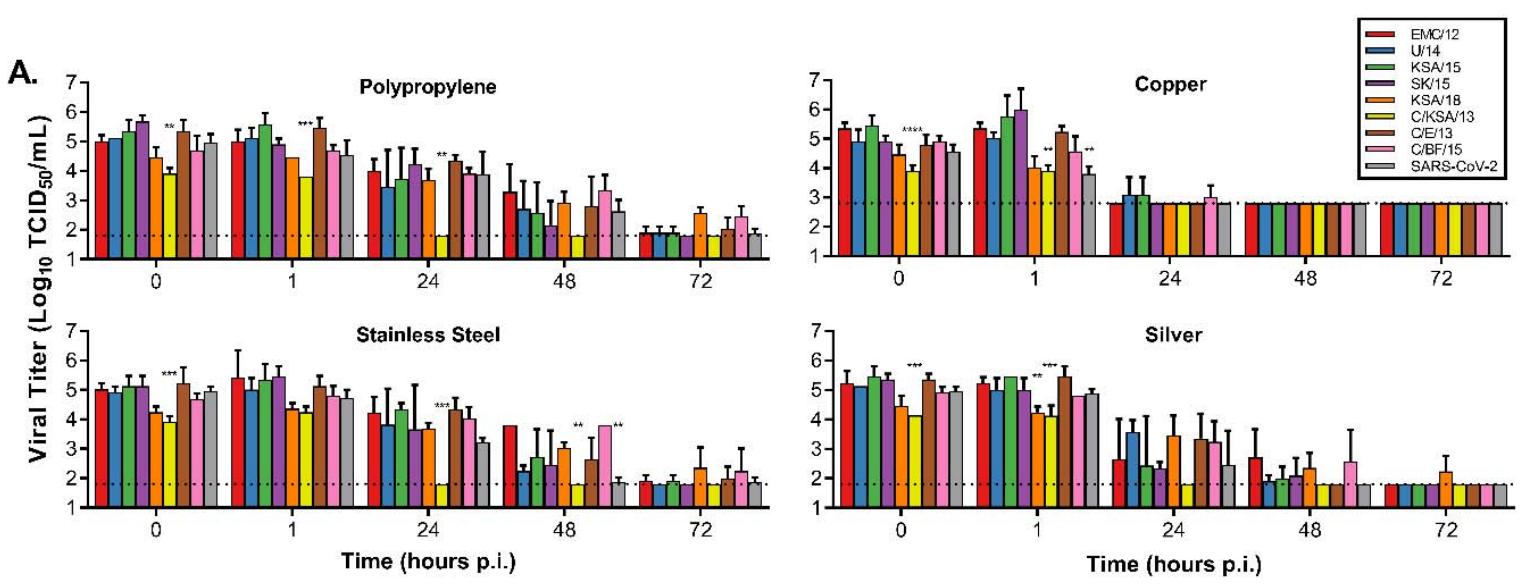

B.
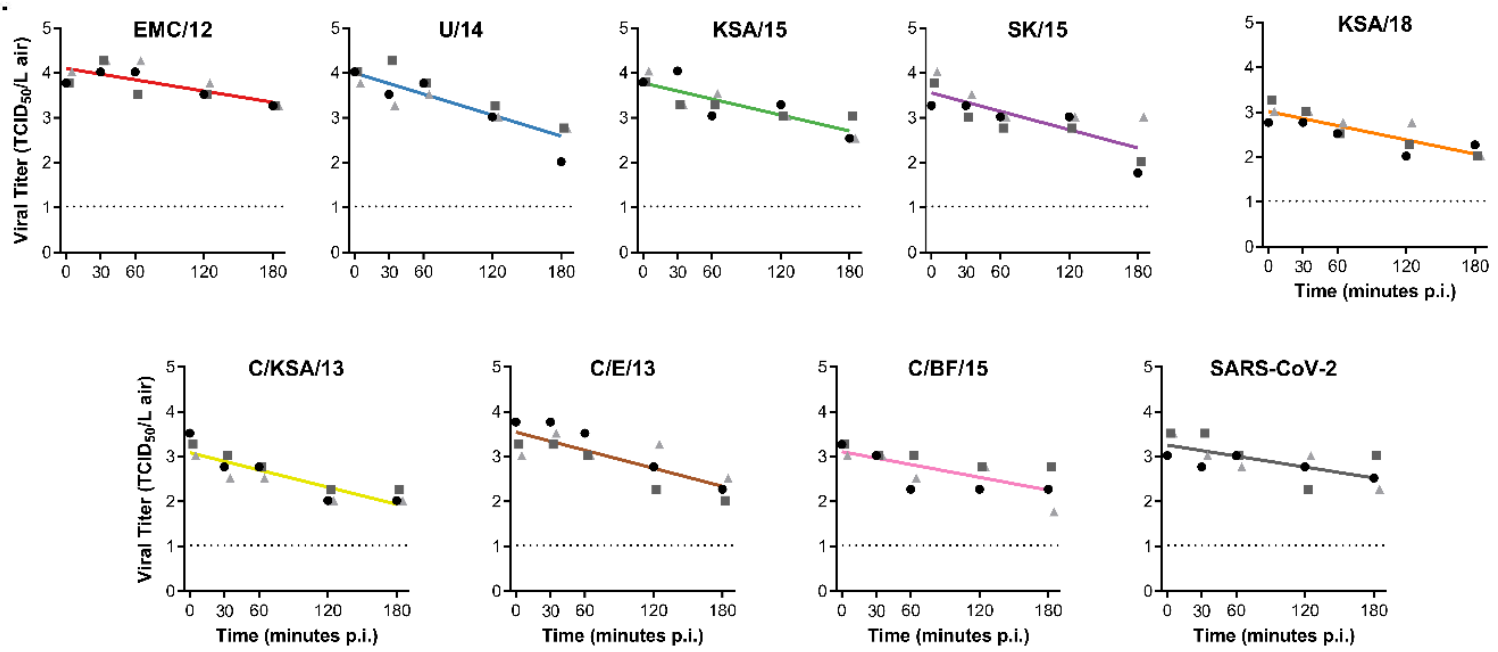

Figure 2. Stability of MERS-CoV strains on surfaces and in aerosols compared to SARSCoV-2. A.) $50 \mu \mathrm{l}$ of MERS-CoV or SARS-CoV-2 was spread on surface, either polypropylene, stainless steel, copper or silver. $1 \mathrm{~mL}$ of DMEM was added at T=0,1, 24, 48 or 72 hours and titrated. B.) MERS-CoV or SARS-CoV-2 containing aerosols were sprayed into the Goldberg drum, and samples were taken at $\mathrm{T}=0,30,60,120$ and 180 minutes and titrated. Linear regression was calculated per virus and displayed in the graph as a line. A-B.) Statistically significant differences between EMC/12 and other strains were calculated using an unpaired Student's two-tailed t-test corrected for multiple comparisons via Bonferroni. Dotted line = limit of detection; p-values $={ }^{*}<0.05 ;{ }^{* *}<0.01,{ }^{* * *}<0.001$ 
A.

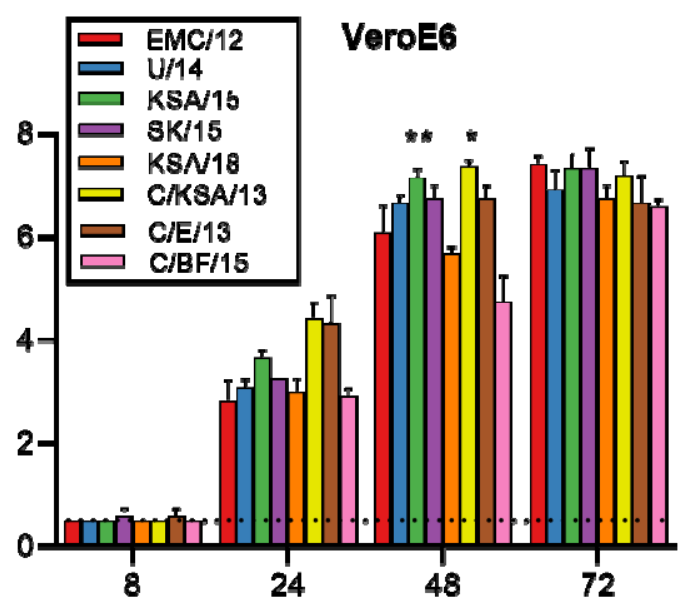

B.

HAE

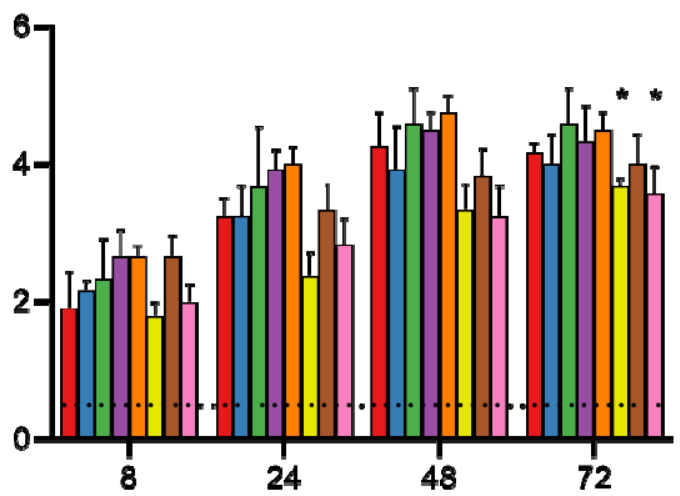

Figure 3. Virus replication in VeroE6 and human airway epithelium. Vero E6 cells $(A)$ or HAE cultures (B) were infected with an $\mathrm{MOI}$ of 0.01 or 0.1 respectively, and samples of supernatant were obtained at 8, 24, 48 and 72 h.p.i. and titrated. Statistically significant differences as compared to the prototypical strain, EMC12, were calculated using an unpaired two-tailed Student's t-test. Dotted line = limit of detection; p-values $={ }^{*}<0.05 ;{ }^{* *}<0.01,{ }^{* * *}<0.001$ 

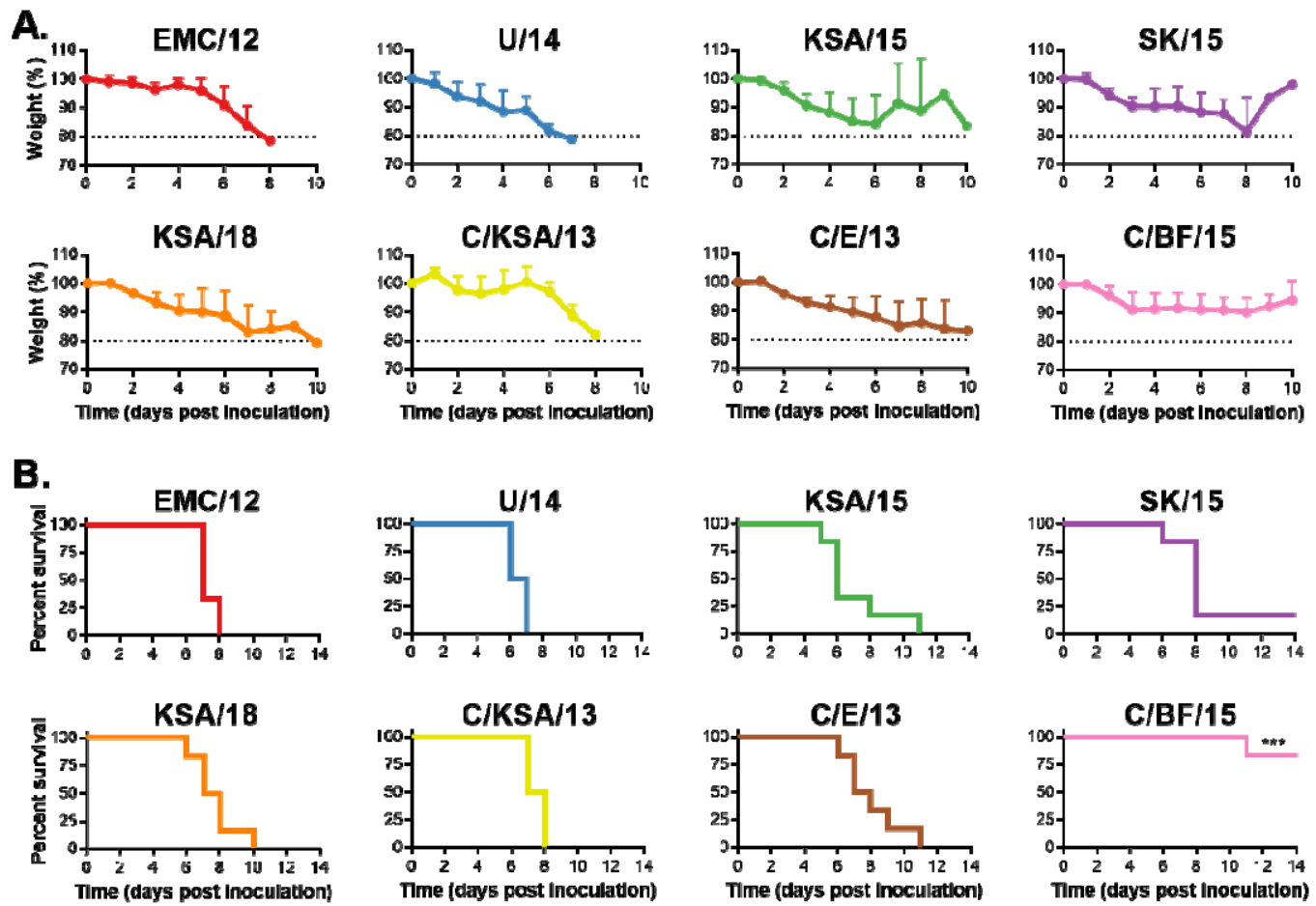

C.
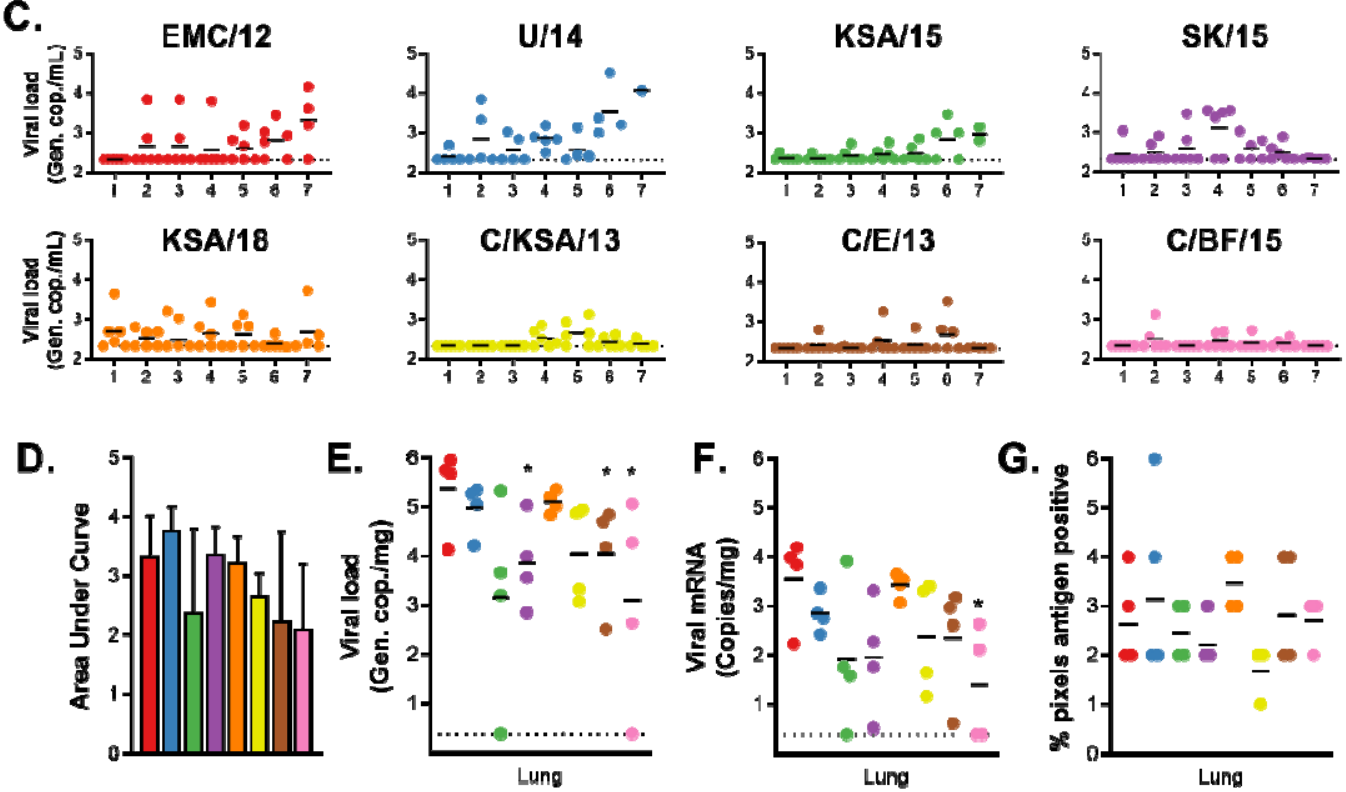

Figure 4. In vivo replication of different MERS-CoV strains. hDPP4 mice were inoculated I.N. with $10^{3} \mathrm{TCID}_{50}$ MERS-CoV. Four mice were euthanized on D3, and the remaining 6 mice were monitored for survival. A.) Relative weight loss of hDPP4 mice. B.) Survival of hDPP4 mice. C.) Oropharyngeal shedding of MERS-CoV as measured via UpE qRT-PCR. D.) Area under the curve of oropharyngeal MERS-CoV shedding per virus strain. E.) Viral load in lung tissue obtained from mice euthanized at D3. F.) Viral mRNA load in lung tissue obtained from mice euthanized at D3. G.) Lung tissue were stained for MERS-CoV antigen and \% of positive 
bioRxiv preprint doi: https://doi.org/10.1101/2021.02.11.429193; this version posted February 12, 2021. The copyright holder for this preprint (which was not certified by peer review) is the author/funder. This article is a US Government work. It is not subject to copyright under 17 USC 105 and is also made available for use under a CCO license.

pixels was quantified. Statistical significance was compared using an unpaired two-tailed Student's t-test. P-value $={ }^{*}<0.05$. 